\title{
Brain Injury in the Premature Infant: Is It Preventable?'
}

\author{
JOSEPH J. VOLPE
}

Departments of Pediatrics, Neurology, and Biological Chemistry, Washington University School of Medicine,
St. Louis, Missouri 63110

The magnitude of the problem of brain injury in the premature infant and, particularly, the prevention of that injury, is enormous. Approximately 42000 infants are born yearly in the United States with a birth weight $\leq 1500 \mathrm{~g}$. Approximately $85 \%$ of these infants survive (1), and of the survivors, approximately $5-15 \%$ exhibit major spastic motor deficits grouped under the rubric "cerebral palsy" and an additional $25-50 \%$ exhibit less prominent developmental disabilities, particularly school failure (2-5). Moreover, data from Sweden (6) and England (7) demonstrate that in recent years the prevalence of cerebral palsy in infants with birth weight $\leq 1500 \mathrm{~g}$ has increased, probably largely secondary to the ever increasing survival rates for these fragile, small infants.

\section{MAJOR NEUROLOGICAL MANIFESTATIONS AND NEUROPATHOLOGY}

The major neurologic manifestations of brain injury in the premature infant are, firstly and uniformly, spastic motor deficits. These deficits consist primarily of spastic quadriparesis, characteristically with greater affection of lower than upper extremities (thus, the term "spastic diplegia"), and spastic hemiparesis. Intellectual deficits are not infrequent accompaniments. Less severe disturbances of motility and cognition occur, as noted above, in $25-50 \%$ of survivors.

The major neuropathology for the spastic motor deficits, with or without accompanying intellectual deficits, are periventricular leukomalacia and periventricular hemorrhagic infarction (previously termed by us "hemorrhagic intracerebral involvement") (8). (Other neuropathologic substrates constitute some of the brain injury in the premature infant, e.g. posthemorrhagic hydrocephalus, pontosubicular necrosis, but on the basis of current data their roles appear to be small when compared to the two neuropathologic states under discussion.) In the following, we will consider periventricular leukomalacia and periventricular hemorrhagic infarction in sequence in terms of 1) the neuropathology, 2) the means of identifying this pathology in vivo in the neonatal period, 3 ) the correlation of the pathology with the subsequent neurologic deficits noted above, 4) the pathogenesis, 5 ) the probable cause(s), and 6) the possibilities for prevention.

\section{PERIVENTRICULAR LEUKOMALACIA.}

Periventricular leukomalacia refers to necrosis of white matter in a characteristic distribution, i.e. the cerebral white matter dorsal and lateral to the external angle of the lateral ventricles (8). Virchow (9) described the lesion over a century ago and several years later Parrot (10) noted that the injury often affected the premature infant. Approximately 60 years later, Rydberg (11)

Correspondence and reprints requests: Dr. Joseph J. Volpe, St. Louis Children's Hospital, 400 South Kingshighway, St. Louis, MO 63110.

'Much of this presentation to the American Pediatric Society in May, 1988 was used in a manuscript published in August, 1989 (Volpe JJ 1989 Current concepts of brain injury in the premature infant. AJR 153:243-251). suggested that the injury was related in some way to circulatory insufficiency at delivery and, in 1961, Schwartz (12) postulated that venous stasis caused by parturient events played a role in pathogenesis. The most lucid and complete description of periventricular leukomalacia is that of Banker and Larroche (13) who, in 1962, described the characteristic topography of the lesion and its cellular characteristics and suggested a relation to arterial border zones. Subsequent work has refined further the pathogenesis of periventricular leukomalacia (see below).

Neuropathology. The neuropathology of periventricular leukomalacia consists of focal necrosis of periventricular white matter, with a particular predilection for the periventricular tissue at the level of the optic radiation adjacent to the trigone of the lateral ventricles and at the level of the frontal cerebral white matter near the foramen of Monro (14). The incidence of such lesions in autopsy studies of premature infants increases as a function of duration of postnatal survival and of frequency and severity of cardiorespiratory disturbances $(14,15)$. In recent years, the incidence in very low birth weight infants has been approximately $25-40 \%(16-18)$.

Less severe examples of periventricular leukomalacia consist of the appearance in the periventricular region of acutely damaged glial cells and astrocytosis (19). Gilles has used the term "perinatal telencephalic leukoencephalopathy" to characterize this less severe neuropathology (19). A minority of examples of periventricular leukomalacia may be complicated by secondary hemorrhage (20), which usually takes the form of multiple petechial hemorrhages within the area of leukomalacia. We believe that this hemorrhagic periventricular leukomalacia should be distinguished from the periventricular hemorrhagic infarction discussed below. Subsequently, with major degrees of periventricular leukomalacia, cystic cavities may develop. With less severe degrees, only diminished cerebral myelin with dilated lateral ventricles will be found.

Diagnosis in the neonatal period. The two principal diagnostic procedures employed to identify periventricular leukomalacia in the living infant are ultrasound scan and CT scan. The former technique is preferable because of its portable instrumentation, high resolution, lack of ionizing radiation, and relative lack of expense.

On ultrasound scan, in the coronal projection, the lesions appear as bilateral, primarily linear echodensities just adjacent to the external angles of the lateral ventricles (8). On parasagittal projections, the echodensities may be diffusely distributed in periventricular white matter or localized to the sites of predilection for periventricular leukomalacia, i.e. the regions adjacent to the trigone of the lateral ventricles and/or adjacent to the ventricles at the level of the foramina of Monro. Interestingly, the pathologic correlate of the echodensities has been primarily nonhemorrhagic periventricular leukomalacia $(21,22)$.

The characteristic evolution of the echodensities of periventricular leukomalacia is the formation of small cysts, often multiple (rendering a "Swiss cheese" appearance) $(21,23,24)$. Cyst 
formation occurs two to three weeks after the appearance of the echodensities. With relatively circumscribed cysts, it is common for the cystic lesions to disappear, at least ultrasonographically, after one to three months, leaving enlarged ventricles with decreased cerebral myelin.

However, it is notable that, in a recent correlative ultrasonographic-neuropathologic study, only $28 \%$ of periventricular white matter lesions were detected in vivo by ultrasonography (25). The lesions missed were diffuse astrocytic gliosis with or without myelin loss and/or focal necrosis (25). The clinical correlate(s) of these missed lesions is (are) not known.

In the newborn, CT scan is a less preferable technique than ultrasonography to demonstrate periventricular leukomalacia because it is difficult to distinguish the lucencies in periventricular white matter that are indicative of periventricular leukomalacia from lucencies that are present in normal infants $(26$, 27). Moreover, CT requires transport of the sick infant and exposure to ionizing radiation. Nevertheless, the technique does demonstrate the lesions well, especially after several weeks when the degree of white matter atrophy can be assessed.

For diagnosis of periventricular leukomalacia, magnetic resonance imaging is of limited value in the neonatal period because of the need to transport the sick infant, the relatively long duration of the study, and the difficulty of monitoring the infant while in the scanner (because of the inability to use metallic monitoring devices and to visualize the infant directly while in the magnet). However, magnetic resonance imaging demonstrates effectively the chronic pathologic consequences of periventricular leukomalacia $(28,29)$.

Clinicopathologic correlations. The major long-term clinical correlates of periventricular leukomalacia are spastic diplegia and, to a lesser extent, intellectual deficits (8). Spastic diplegia is a type of spastic quadriparesis in which lower extremities are affected more than upper extremities. Three major lines of evidence indicate that periventricular leukomalacia results in spastic diplegia. First, the topography of the lesion includes the region of cerebral white matter traversed by descending fibers from motor cortex, and those fibers subserving function of lower extremities are more likely to be affected by the periventricular locus of the necrosis. Second, the periventricular echodensities visualized by ultrasound in the neonatal period and shown to reflect periventricular leukomalacia by postmortem studies have been documented repeatedly by ourselves and others (23) to be followed by the development of spastic diplegia. Third, both periventricular leukomalacia and spastic diplegia have been known for many years to be characteristic consequences of premature birth.

The extent of the role of periventricular white matter injury in the genesis of intellectual deficits is not entirely clear. Certainly, infants with the largest lesions and marked spastic diplegia are often intellectually deficient. It is noteworthy that the sites of predilection for periventricular leukomalacia include the fibers subserving association of visual, auditory, and somesthetic functions, so critical for learning. Perhaps of major importance is the possibility that the less prominent developmental disabilities and school failure seen in a relatively large proportion of premature infants (see above) are, at least in part, due to the smaller degrees of injury to periventricular white matter that are so frequently missed by neonatal cranial ultrasonography (see above).

Pathogenesis. Pathogenesis of periventricular leukomalacia relates to three principal factors (Table 1). First, certain periventricular vascular anatomic factors appear to render this region of the brain of the premature infant vulnerable to cerebral ischemia.

\section{Table 1. Pathogenesis of periventricular leukomalacia}

\footnotetext{
1. Periventricular vascular anatomic factors.

2. Pressure-passive cerebral circulation.

3. Enhanced vulnerability of actively differentiating and/or myelinating periventricular glial cells.
}

Thus, extending the basic observations of Van den Bergh and Vander Eecken, DeReuck and coworkers (30-34) have demonstrated the presence in the periventricular region of arterial border zones and end zones. These arterial border and end zones are essentially "distal fields," i.e. watershed zones that would be expected to be most vulnerable to a fall in perfusion pressure and cerebral blood flow. Moreover, DeReuck (32) and Takashima and Tanaka (35) have shown that the border zones in periventricular white matter are most prominent in the least mature infants because of the development of the periventricular microvascular network. Additionally, premature infants with periventricular leukomalacia and no obvious history of circulatory disturbance were usually the most premature infants, whereas those infants with periventricular leukomalacia and a history of circulatory disturbance were more often less premature. These data suggest that the degree of ischemia required to produce periventricular leukomalacia is dependent upon the developmental state of the periventricular vessels, and that this state is primarily a function of gestational age. At any rate, the arterial border zones and end zones in the periventricular region have a characteristic distribution, and it is within these zones that periventricular leukomalacia occurs. Indeed, the most frequent loci for periventricular leukomalacia are within the two distinctive anterior and posterior periventricular border zones (see Neuropathology).

Second, a pressure-passive cerebral circulation (Table 1) appears to exist in the premature infant, particularly the sick infant, and this phenomenon would render the infant susceptible to decreases in cerebral blood flow and injury to periventricular white matter with hypotension. Thus, a linear direct relation between systolic blood pressure and cerebral blood flow measured by the ${ }^{133} \mathrm{Xe}$ clearance technique (36) was documented in the first hours of life in a series of premature infants. With intact cerebrovascular autoregulation, cerebral blood flow should not be pressure-passive but rather should remain constant over a wide range of blood pressure because of arteriolar constriction with elevations of blood pressure and arteriolar dilation with decreases of blood pressure. Recent data suggest that clinically stable premature infants do not exhibit this pressure-passive cerebral circulation (37-39). Experimental and human studies (8) suggest that the pressure-passive circulatory abnormality could result from: $I$ ) the hypercarbia or hypoxemia (or both) of perinatal asphyxia, respiratory disease, and/or "normal" vaginal delivery; 2) the cranial "trauma" to the easily deformed premature head at the time of normal vaginal delivery; 3) an "immature" autoregulatory system related to the deficient muscularis of cerebral arterioles in the premature infant; 4) the occurrence of normal blood pressures that are dangerously close to the down slope of a normal autoregulatory curve; or 5) a combination of these factors. Whatever the mechanism(s), the clinical implications are enormous. Falls in arterial blood pressure may lead to seriously lowered cerebral blood flow and, ultimately, ischemic injury to vulnerable regions such as the periventricular white matter. Decreases in systemic blood pressure in the premature may result from such events as perinatal asphyxia, patent ductus arteriosus (40), myocardial failure, apneic spells with bradycardia (41), sepsis, and even simple handling with caretaking procedures (42).

Third, coupled with the pressure-passive circulatory disturbance are factors that indicate an enhanced vulnerability of the actively differentiating and/or myelinating periventricular glial cells (Table 1). Thus, experimental studies of neonatal animals have shown a limited increase in cerebral blood flow in the periventricular white matter, presumably because of limited vasodilatory capacity, to such potent stimuli as hypoxemia, hypercarbia, and hypotension (43-46). Moreover, when compared to other brain regions, the periventricular white matter of the neonatal (or fetal) animal subjected to hypoxic-ischemic insult exhibits a degree of active anaerobic glycolysis that exceeds substrate supplies and leads to accumulation of lactic acid and 
depletion of high energy compounds in cerebral white matter (43-47). These latter two metabolic effects occur presumably because of the combination of the aforementioned limited vasodilatory capacity and the relatively active glycolytic capacity of periventricular glial cells. Finally, and perhaps related to the two factors just described, it is likely that the glial cells in periventricular white matter are intrinsically vulnerable to injury because they are in a developmental stage of active differentiation to astrocytes and to oligodendroglia. Moreover, some of the latter have begun active myelination in the perinatal period, and the distribution of hypoxic-ischemic periventricular white matter injury includes areas of early myelinating activity in particular (19).

Probable cause(s) and prevention. The discussion of pathogenesis above leads to the conclusion that periventricular leukomalacia is caused primarily by systemic hypotension, sufficiently severe to lead to impaired cerebral blood flow. Thus, prevention will depend particularly on careful monitoring of circulatory status, prompt management of those events (e.g. sepsis, apneic spells) that lead to circulatory failure, and prompt therapy for such failure. However, it is likely that in the most immature infants, because of periventricular vascular factors related to maturation-dependent deficiencies of the periventricular microcirculatory network (see above), periventricular leukomalacia may occur with systemic disturbances so slight that they escape detection by even careful monitoring. Further delineation of pathogenesis, detection of imminent injury, and formulation of interventions to protect vulnerable periventricular tissue will be needed to prevent the entire spectrum of periventricular leukomalacia.

\section{PERIVENTRICULAR HEMORRHAGIC INFARCTION}

Periventricular hemorrhagic infarction refers to hemorrhagic necrosis of periventricular white matter that is usually large and almost invariably asymmetric. Most often, the lesion coexists with intraventricular hemorrhage and, indeed, approximately $15 \%$ of all infants with intraventricular hemorrhage also exhibit periventricular hemorrhagic infarction (8). In contrast to periventricular leukomalacia, this lesion does not have a long history in the medical literature and, in fact, we believe that its current prominence relates to the recent increase in survival of very small premature infants.

Neuropathology. The neuropathology of periventricular hemorrhagic infarction is striking and consists of a relatively large region of hemorrhagic necrosis in the periventricular white matter, just dorsal and lateral to the external angle of the lateral ventricle. The necrosis is strikingly asymmetric-in the largest series reported (48), $67 \%$ of such lesions were exclusively unilateral and, in virtually all of the remaining cases, grossly asymmetric, even though bilateral. Approximately one-half of the lesions are extensive and involve the periventricular white matter from frontal to parieto-occipital regions; the remainder are more localized. Approximately $80 \%$ of cases are associated with large intraventricular hemorrhage, and, commonly (and mistakenly), the parenchymal hemorrhagic lesion is described as "extension" of the hemorrhage. That simple extension of blood into cerebral white matter from germinal matrix or lateral ventricle does not account for the periventricular hemorrhagic necrosis has been shown clearly by several neuropathologic studies (48-54).

Microscopic study of this periventricular hemorrhagic necrosis indicates that the lesion is a hemorrhagic infarction $(48,49,51-$ 54). The careful studies of Gould et al. (53) and Takashima et al. (55) emphasize that: 1 ) the hemorrhagic component usually consists of perivascular hemorrhages that follow closely the fanshaped distribution of the medullary veins in periventricular white matter, and 2) the hemorrhagic component tends to be most concentrated near the ventricular angle where these veins become confluent and ultimately join the terminal vein in the subependymal region. Thus, it appears likely that periventricular hemorrhagic necrosis occurring in association with large intraventricular hemorrhage is, in fact, a venous infarction. This lesion is distinguishable neuropathologically from secondary hemorrhage into periventricular leukomalacia, the ischemic, usually nonhemorrhagic, and symmetric lesion of periventricular white matter of the premature infant (see above). However, distinction of these two lesions in vivo often is very difficult. In Table 2, we compare the basic features of these two periventricular white matter lesions of the premature infant.

Diagnosis in the neonatal period. The two principal diagnostic procedures used to identify periventricular hemorrhagic infarction in vivo are ultrasound scan and CT scan. As noted for periventricular leukomalacia, ultrasonography is the preferred procedure.

On ultrasound scan, in the coronal projection, the lesions appear as unilateral or, if bilateral, clearly asymmetric, globular or triangular ("fan-shaped") echodensities radiating from the external angle of the lateral ventricle. On parasagittal projections, the extent of the lesion is visualized best and may be classified as extensive (i.e. extending from frontal to parieto-occipital regions) or localized (i.e. involving only the frontal, parietal, or parieto-occipital region).

The characteristic ultrasonographic evolution of the large echodensities is to cyst formation; these cysts, unlike the cysts of periventricular leukomalacia, tend to be single and large. Also, unlike the cysts of periventricular leukomalacia, the cysts that form after periventricular hemorrhagic infarction rarely disappear over time.

CT scan is a less preferable technique to demonstrate the acute lesion of periventricular hemorrhagic infarction for the reasons outlined regarding diagnosis of periventricular leukomalacia. However, the full extent of the periventricular parenchymal injury in the months after the acute period is delineated especially well by CT. Similarly, although not practical during the acute period, magnetic resonance imaging is particularly effective in demonstrating the extent of parenchymal destruction in the months following the neonatal period.

Although not generally available, positron emission tomography and, specifically, the measurement of regional cerebral blood flow thereby, has been used to show that the full extent of the white matter injury in periventricular hemorrhagic infarction may be underestimated by cranial ultrasonography (52). This underestimation relates presumably to the fact that the full extent of the infarction may not be hemorrhagic and, thus, may not be demonstrated unequivocally by ultrasound scan.

Clinicopathologic correlations. The major long-term correlates of periventricular hemorrhagic infarction are spastic hemiparesis (or asymmetric quadriparesis) and intellectual deficits. The spastic hemiparesis characteristically affects lower extremities as much as upper extremities, presumably because the periventricular locus of the lesion affects descending fibers from the lower extremity region of motor cortex as much as those from the upper extremity region. (This topography is different from the more laterally-placed middle cerebral artery infarct of the asphyxiated full-term infant, which results in affection of upper more than lower extremity.)

The overall outcome of the largest reported series of infants with presumed periventricular hemorrhagic infarction, identified on ultrasound scan as intraparenchymal echodensity (IPE) greater than $1 \mathrm{~cm}$, was unfavorable (48). For the 75 infants studied, the mortality rate was $59 \%$. (This should be contrasted with a mortality rate of $8 \%$ in the same neonatal unit at the same time for infants with the severest grade of IVH, i.e. grade III IVH, but no associated IPE.) Among the 22 survivors who could be examined on followup, $86 \%$ exhibited major motor deficits and $64 \%$ had cognitive function less than $80 \%$ of normal. The motor deficits correlated with the topography of the IPE, and thus consisted of either spastic hemiparesis or asymmetric spastic quadriparesis.

Prognostic estimation could be refined further by considering 
Table 2. Periventricular white matter lesions in premature infant with intraventricular hemorrhage

\begin{tabular}{cccc}
\hline $\begin{array}{c}\text { Proposed } \\
\text { designation }\end{array}$ & \multicolumn{1}{c}{$\begin{array}{c}\text { Markedly } \\
\text { asymmetric }\end{array}$} & \multicolumn{1}{c}{$\begin{array}{c}\text { Grossly } \\
\text { hemorrhagic }\end{array}$} & $\begin{array}{c}\text { Probable site of } \\
\text { circulatory disturbance }\end{array}$ \\
\hline $\begin{array}{l}\text { Periventricular leukomalacia } \\
\text { Periventricular hemorrhagic infarction }\end{array}$ & $\begin{array}{l}\text { Uncommon } \\
\text { Nearly invariable }\end{array}$ & Uncommon & Arterial \\
Invariable & Venous & . \\
\hline
\end{tabular}

Table 3. Outcome of premature infants with major intraparenchymal echodensity (IPE) as function of severity

\begin{tabular}{lcrr}
\hline \multirow{2}{*}{ Outcome } & \multicolumn{3}{c}{ Severity of IPE* } \\
\cline { 2 - 4 } & \multicolumn{2}{c}{ Extensive } & \multicolumn{1}{c}{ Localized } \\
\hline Mortality & $30 / 37$ & $(81 \%)$ & $14 / 38(37 \%)$ \\
Major motor deficits & $7 / 7$ & $(100 \%)$ & $12 / 15(80 \%)$ \\
Cognitive $<80 \% \dagger$ & $6 / 7$ & $(85 \%)$ & $8 / 15(53 \%)$ \\
Normal survivor $\ddagger$ & $0 / 37$ & $(0 \%)$ & $3 / 29(10 \%)$ \\
\hline
\end{tabular}

* Severity classified extensive if IPE extended from frontal to parietooccipital regions and localized if IPE confined to the frontal, parietal, or parieto-occipital region, as visualized on parasagittal ultrasound scan.

$\dagger$ Cognitive function $<80 \%$ of average for age; psychometric tests used were different because they were chosen according to age and best abilities of the patient.

$\ddagger$ Surviving infant free of motor deficit with cognitive function $>80 \%$ of average.

Table 4. Association between occurrence of intraparenchymal echodensity (IPE*) and severity of intraventricular hemorrhage (IVH)

\begin{tabular}{cc}
\hline Severity of & Number (\%)‡ with \\
IVH $\dagger$ & IPE \\
\hline Grade III & $58(77 \%)$ \\
Grades I-II & $13(18 \%)$ \\
None & $4(5 \%)$ \\
\hline
\end{tabular}

* IPE was defined as (periventricular) intraparenchymal echodensity $>1 \mathrm{~cm}$ in at least one dimension on ultrasound scan.

$\dagger$ Severity graded I to III according to increasing amount of blood in lateral ventricles, as described previously (8).

$\ddagger$ Percentage of all patients with IPE.

the severity of the IPE (Table 3). Thus, among infants with extensive IPE (i.e. IPE that included fronto-parieto-occipital regions), 30 of 37 ( $81 \%$ ) died, and of the seven survivors, all had subsequent motor deficits. Overall, only one of the 37 infants with extensive IPE survived to have an I.Q. score greater than 80 , and none were completely normal, i.e. free of motor deficit and I.Q. greater than 80 .

Among infants with localized IPE (i.e. IPE confined to either the frontal, parietal, or parieto-occipital regions), outcome was more favorable than after extensive IPE. Of the 38 infants with localized IPE, 14 (37\%) died. Of the 15 survivors who could be followed subsequently, three were free of major motor deficit and seven had psychometric test scores in excess of $80 \%$ of normal. Overall, three (10\%) of the 29 infants with localized IPE and known outcome had both normal motor and cognitive function subsequently. The subset of eight infants with localized IPE that was unilateral had the most favorable cognitive outcome of all, i.e. only one had a psychometric test score less than $70 \%$ of normal.

Pathogenesis. The pathogenesis of the periventricular hemorrhagic necrosis that appears to be a venous infarction is not entirely established. However, a direct relation to germinal matrix-intraventricular hemorrhage seems likely on the basis of three recently defined facts (48). First, approximately $80 \%$ of the parenchymal lesions were observed in association with large (and usually asymmetric) intraventricular hemorrhage (Table 4). Second, the parenchymal lesions occurred invariably on the same side as the larger amount of intraventricular blood (Table 5). Third, the parenchymal lesions developed and progressed after
Table 5. Relation of side of intraparenchymal echodensity (IPE) with side of asymmetric intraventricular hemorrhage $(I V H)^{*}$

\begin{tabular}{ccc}
\hline $\begin{array}{c}\text { Severity of } \\
\text { IVH }\end{array}$ & $\begin{array}{c}\text { IPE } \\
\text { homolateral } \dagger\end{array}$ & $\begin{array}{c}\text { IPE } \\
\text { contralateral } \dagger\end{array}$ \\
\hline Grades III & 47 & 0 \\
Grades I-II & 5 & 4 \\
\hline
\end{tabular}

* Numbers refer to numbers of those patients with asymmetric IVH.

$\dagger$ IPE homolateral refers to IPE on same side as larger amount of intraventricular blood; IPE contralateral refers to IPE on opposite side of larger amount of intraventricular blood.

the occurrence of the IVH. The peak time of their occurrence was the fourth postnatal day (48), i.e. when $90 \%$ of cases of intraventricular hemorrhage have already occurred (8). These data raised the possibility that the intraventricular hemorrhage and/or its associated germinal matrix hemorrhage led to obstruction of the terminal veins and hemorrhagic venous infarction. A similar conclusion has been suggested from a recent neuropathologic study (53). Nevertheless, experimental studies raise the possibility that the intraventricular blood could contribute to the periventricular necrosis by causing: $l$ ) impairment of periventricular blood flow secondary to increased intraventricular pressure (56) and/or local release of $\mathrm{K}^{+}$from hemolyzed red blood cells (57); or 2) local release by red blood cells of lactic acid (58), or perhaps other vasoactive or otherwise injurious compounds. On balance, however, we consider most probable the pathogenetic notion of obstruction of medullary and terminal veins by intraventricular and germinal matrix blood clot.

Thus, the pathogenetic scheme that we consider to account for most examples of periventricular hemorrhagic infarction is shown in Figure 1. This scheme should be distinguished from that operative for hemorrhagic periventricular leukomalacia (Fig. 2 ), although clearly the lesions may coexist. The frequency of coexistence of the two lesions is not known. Additionally, the two pathogenetic schemes could operate in sequence, i.e. periventricular leukomalacia could become hemorrhagic (and perhaps a larger area of injury) when germinal matrix or intraventricular hemorrhage subsequently causes venous obstruction.

Probable cause(s) and prevention. The discussion of pathogenesis above leads to the conclusion that the major cause of periventricular hemorrhagic infarction is germinal matrix-intraventricular hemorrhage. Thus, prevention of the infarction centers around prevention of the hemorrhage. Although several approaches have been reported to be at least partially effective for prevention (8), we have favored the use of muscle paralysis (59).

As noted above, it is possible that a minority of cases of periventricular hemorrhagic infarction are related to cerebral ischemia and the initial occurrence of periventricular leukomalacia. In such cases, prevention would center around prevention of impaired cerebral blood flow. Therefore, the measures described above in relation to causation and prevention of periventricular leukomalacia are relevant in this context.

\section{CONCLUSION}

There are two principal lesions that underlie the brain injury and the neurologic manifestations thereof in the premature infant, i.e. periventricular leukomalacia and periventricular hemorrhagic infarction. Both of these lesions may be largely preventable-periventricular leukomalacia by preventing impaired cerebral blood flow, particularly secondary to systemic hypotension, 
GERMINAL MATRIX -

INTRAVENTRICULAR

HEMORRHAGE

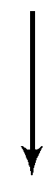

PERIVENTRICULAR VENOUS

CONGESTION

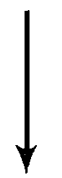

\section{PERIVENTRICULAR ISCHEMIA}

\section{PERIVENTRI ICULAR HEMORRHAGIC INFARCTION}

Fig. 1. Pathogenesis of periventricular hemorrhagic infarction. Formulation indicates a major role for germinal matrix and/or intraventricular hemorrhage in causation of the periventricular venous (hemorrhagic) infarction.

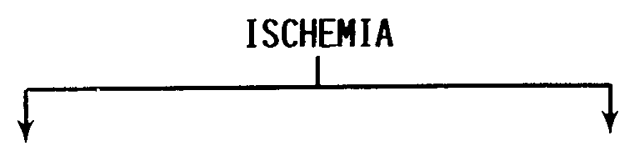

PERIVENTRICULAR

LEUKOMALACIA

(NON-HEMORRHAGIC INFARCTION)

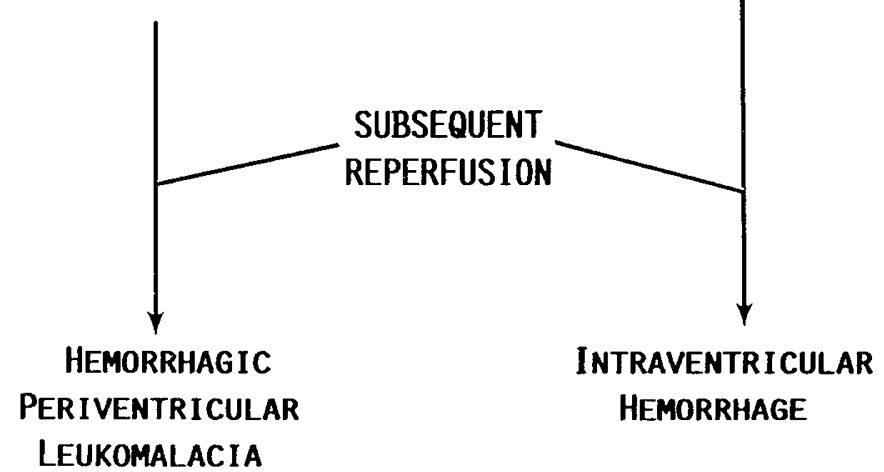

Fig. 2. Pathogenesis of hemorrhagic periventricular leukomalacia.

and periventricular hemorrhagic infarction, by preventing germinal matrix-intraventricular hemorrhage.

\section{REFERENCES}

1. Horbar JD, McAuliffe, TL, Adler SM, Albersheim S, Cassady G, Edwards W, Jones R, Kattwinkel J, Kraybill EN, Krishnan V, Raschko P, Wilkinson AR 1988 Variability in 28-day outcomes for very low birth weight infants: an analysis of 11 neonatal intensive care units. Pediatrics 82:554-559

2. Calame A, Fawer CL, Claeys V, Arrazola L, Ducret S, Jaunin L 1986 Neurodevelopmental outcome and school performance of very-low-birth weight infants at 8 years of age. Eur J Pediatr 145:461-466
3. Fawer CL, Diebold P, Calame A 1987 Periventricular leukomalacia and neurodevelopmental outcome in preterm infants. Arch Dis Child 62:30-36

4. Blennow $\mathrm{G}$, Pleven $\mathrm{H}$, Lindroth M, Johansson $\mathrm{G} 1986$ Longterm follow-up of ventilator treated low birthweight infants. Acta Paediatr Scand 75:827-831

5. Stewart A, Hope PL, Hamilton P, Costello AM de-L, Baudin J, Bradford B, Amiel-Tison C, Reynolds EOR 1988 Prediction in very preterm infants of satisfactory neurodevelopmental progress at 12 months. Dev Med Child Neurol 30:53-63

6. Hagberg B, Hagberg G, Olow I 1984 The changing panorama of cerebral palsy in Sweden. Acta Paediatr Scand 73:433-440

7. Pharoah POD, Cooke T, Rosenbloom I, Cooke RWI 1987 Trends in birth prevalence of cerebral palsy. Arch Dis Child 62:379-384

8. Volpe JJ 1987 Neurology of the Newborn. WB Saunders, Philadelphia, pp $160-280$

9. Virchow R 1867 Zur pathologischen anatomie des gehirns. I. Congenitale encephalitis and myelitis. Virchows Arch [A] 38:129-141

10. Parrot J 1873 Etude sur le ramollissement de l'encephale chez le nouveau-ne. Arch Physiol Norm Pathol 5:59-75

11. Rydberg E 1932 Cerebral injury in newborn children, consequent on birth trauma: With an inquiry into the normal and pathological anatomy of the neuroglia. Acta Pathol Microbiol Immunol Scand [Suppl] 19S:1-31

12. Schwartz P 1961 Birth Injuries of the Newborn: Morphology, Pathogenesis, Clinical Pathology and Prevention. Hafner Publ Co, New York

13. Banker BQ, Larroche JC 1962 Periventricular leukomalacia of infancy. Arch Neurol 7:32-50

14. Shuman RM, Selednik LL 1980 Periventricular leukomalacia. A one-year autopsy study. Arch Neurol 37:231-239

15. Barth PG, Stam FC, Oosterkamp RF, Bezemer PD, Koopman PA 1980 On the relationship between germinal layer haemorrhage and telencephalic leucoencephalopathy in the preterm infant. Neuropediatrics 11:17-24

16. Pape KE, Armstrong DL, Fitzhardinge PM 1976 Central nervous system pathology associated with mask ventilation in the very low birthweight infant: a new etiology for intracerebellar hemorrhage. Pediatrics 58:473-481

17. Skullerud K, Westre B 1986 Frequency and prognostic significance of germinal matrix hemorrhage, periventricular leukomalacia, and pontosubicular necrosis in preterm neonates. Acta Neuropathol (Berl) 70:257-261

18. Larroche JC 1982 Hypoxic brain damage in fetus and newborn. Morphological characters. Pathogenesis. Prevention. J Perinat Med 10(S)2:29-31

19. Gilles FH, Leviton A, Dooling EC 1983 The Developing Human Brain: Growth and Epidemiologic Neuropathology. John Wright, Boston

20. Armstrong D, Norman MG 1974 Periventricular leukomalacia in neonates: complications and sequelae. Arch Dis Child 49:367-374

21. McMenamin JB, Shackelford GD, Volpe JJ 1984 Outcome of neonatal intraventricular hemorrhage with periventricular echodense lesions. Ann Neurol 15:285-290

22. Nwaesei CG, Pape KE, Martin DJ, Becker LE, Fitz CH 1984 Periventricular infarction diagnosed by ultrasound: a postmortem correlation. J Pediatr 105:106-110

23. Bowerman RA, Donn SM, DiPietro MA, Damato CJ, Hicks SP 1984 Periventricular leukomalacia in the pre-term newborn infant: sonographic and clinical features. Radiology 151:383-390

24. Dubowitz LMS, Bydder GM, Muschin J 1985 Developmental sequence of periventricular leukomalacia. Arch Dis Child 60:349-358

25. Hope PL, Gould SJ, Howard S, Hamilton PA, Costello AM de-L, Reynolds EOR 1988 Precision of ultrasound diagnosis of pathologically verified lesions in the brains of very preterm infants. Dev Med Child Neurol 30:457-471

26. DiChiro G, Arimitsu T, Pellock JM, Landes RD 1978 Periventricular leukomalacia related to neonatal anoxia: recognition by computed tomography. $J$ Comput Assist Tomogr 2:352-359

27. Estrada M, Gammal TE, Dyken PR 1980 Periventricular low attenuations. Arch Neurol 37:754-760

28. Flodmark O, Roland EH, Hill A, Whitfield MF 1987 Periventricular leukomalacia: radiologic diagnosis. Radiology 162:119-124

29. Baker LL, Stevenson DK, Enzmann DR 1988 End-stage periventricular leukomalacia: MR evaluation. Radiology 168:809-815

30. DeReuck J 1971 The human periventricular arterial blood supply and the anatomy of cerebral infarctions. Eur Neurol 5:321-329

31. DeReuck J, Chattha AS, Richardson Jr EP 1972 Pathogenesis and evolution of periventricular leukomalacia in infancy. Arch Neurol 27:229-238

32. DeReuck JL 1984 Cerebral angioarchitecture and perinatal brain lesions in premature and full term infants. Acta Neurol Scand 70:391-399

33. Van den Bergh R, Vander Eecken H 1968 Anatomy and embryology of the cerebral circulation. Prog Brain Res 30:1-26

34. Van den Bergh R 1969 Centrifugal elements in the vascular pattern of the intracerebral blood supply. Angiologia 20:88-98

35. Takashima S, Tanaka K 1978 Development of cerebrovascular architecture and its relationship to periventricular leukomalacia. Arch Neurol 35:1 1-19

36. Lou HC, Lassen NA, Friis-Hansen B 1979 Impaired autoregulation of cerebral blood flow in the distressed newborn infant. J Pediatr 94:1 18-125

37. Younkin DP, Reivich M, Jaggi JL, Obrist WD, Delivoria-Papadopoulos M 1987 The effect of hematocrit and systolic blood pressure on cerebral blood flow in newborn infants. J Cereb Blood Flow Metab 7:295-299

38. Greisen $G 1986$ Cerebral blood flow in preterm infants during the first week of life. Acta Paediatr Scand 75:43-51

39. Greisen G, Trojaborg W 1987 Cerebral blood flow, $\mathrm{PaCO}_{2}$ changes, and visual evoked potentials in mechanically ventilated, preterm infants. Acta Paediatr Scand 76:394-400 
40. Perlman JM, Hill A, Volpe JJ 1981 The effect of patent ductus arteriosus on flow velocity in the anterior cerebral arteries: ductal steal in the premature newborn infant. J Pediatr 99:767-771

41. Perlman JM, Volpe JJ 1985 Episodes of apnea and bradycardia in the preterm newborn: impact on the cerebral circulation. Pediatrics 76:333-338

42. Omar SY, Greisen G, Ibrahim MM, Youssef AM, Friis-Hansen B 1985 Blood pressure responses to care procedures in ventilated preterm infants. Acta Paediatr Scand 74:920-924

43. Duffy TE, Cavazzutti M, Cruz NF, Sokoloff L 1982 Local cerebral glucose metabolism in newborn dogs. Ann Neurol 11:233-239

44. Cavazzutti M, Duffy TE 1982 Regulation of local cerebral blood flow in normal and hypoxic newborn dogs. Ann Neurol 11:247-254

45. Young RSK, Hernandez MJ, Yagel SK 1982 Selective reduction of blood flow to white matter during hypotension in newborn dogs: a possible mechanism of periventricular leukomalacia. Ann Neurol 12:445-452

46. Rice JE III, Vannucci RC, Brierley JB 1981 The influence of immaturity on hypoxic-ischemic brain damage in the rat. Ann Neurol 9:131-141

47. Wagner KR, Ting P, Westfall MV, Yamaguchi S, Bacher JD, Myers RE 1986 Brain metabolic correlates of hypoxic-ischemic cerebral necrosis in midgestational sheep fetuses: Significance of hypotension. J Cereb Blood Flow Metab 6:425-434

48. Guzzetta F, Shackelford GD, Volpe S, Perlman JM, Volpe JJ 1986 Periventricular intraparenchymal echodensities in the premature newborn: critical determinant of neurological outcome. Pediatrics 78:995-1006

49. McMenamin JB, Shackelford GD, Volpe JJ 1984 Outcome of neonatal intraventricular hemorrhage with periventricular echodense lesions. Ann Neurol $15: 285-290$

50. Armstrong DL, Sauls CD, Goddard-Finegold J 1987 Neuropathologic findings in short-term survivors of intraventricular hemorrhage. Am J Dis Child 141:617-621

51. Flodmark O, Becker LE, Harwood-Nash DC, Futzhardinge PM, Fitz CR, Chuang SH 1980 Correlation between computed tomography and autopsy in premature and full-term neonates that have suffered perinatal asphyxia. Radiology 137:93-103

52. Volpe JJ, Herscovitch P, Perlman JM, Raichle ME 1983 Positron emission tomography in the newborn: extensive impairment of regional cerebral blood flow with intraventricular hemorrhage and hemorrhagic intracerebral involvement. Pediatrics 72:589-601

53. Gould SJ, Howard S, Hope PL, Reynolds EOR 1987 Periventricular intraparenchymal cerebral haemorrhage in preterm infants: the role of venous infarction. J Pathol 151:197-202

54. Rushton DI, Preston PR, Durbin GM 1985 Structure and evolution of echo dense lesions in the neonatal brain. Arch Dis Child 60:798-808

55. Takashima S, Mito T, Ando Y 1986 Pathogenesis of periventricular white matter hemorrhages in preterm infants. Brain Dev 8:25-30

56. Batton DG, Nardis EE 1987 The effect of intraventricular blood on cerebral blood flow in newborn dogs. Pediatr Res 21:511-515

57. Edvinsson L, Lou HC, Tvede K 1986 On the pathogenesis of regional cerebral ischemia in intracranial hemorrhage: a causal influence of potassium? Pediatr Res 20:478-480

58. Pranzatelli MR, Stumpf DA 1985 The metabolic consequences of experimental intraventricular hemorrhage. Neurology 35:1299-1303

59. Perlman JM, Goodman S, Kreusser KL, Volpe JJ 1985 Reduction in intraventricular hemorrhage by elimination of fluctuating cerebral blood-flow velocity in preterm infants with respiratory distress syndrome. N Engl J Med 313:1353-1357 